\title{
A comparative study of basic types of energy meters and metering
}

\author{
Chioma Lizzy Nwagbo ${ }^{1}$ and Barida Baah 2,* \\ ${ }^{1}$ Department of Computer Science and Robotics Education, College of Education, Nsugbe, Anambra State, Nigeria. \\ 2 Department of Computer Science, Ebonyi State University, Abakaliki- Nigeria.
}

Global Journal of Engineering and Technology Advances, 2022, 10(01), 117-124

Publication history: Received on 22 December 2021; revised on 27 January 2022; accepted on 29 January 2022

Article DOI: https://doi.org/10.30574/gjeta.2022.10.1.0028

\begin{abstract}
This research work compares basic types of energy meter and metering with the view of discussing the various types taking a critical look at its merits and demerits and also comparing the efficiency in terms of performance. The benefit of this research work is to ensure that adequate energy metering is use for any given meter to provide efficient services to consumers of electric powers.
\end{abstract}

Keywords: Electromechanical; Meter; Energy meter and Metering

\section{Introduction}

An electricity meter, electric meter, electrical meter, or energy meter is a device that measures the amount of electric energy consumed by a residence, a business, or an electrically powered device. .Electric utilities use electric meters installed at customers' premises for billing purposes. They are typically calibrated in billing units, the most common one being the kilowatt hour $(k W h)$. They are usually read once each billing period. When energy savings during certain periods are desired; some meters may measure demand, the maximum use of power in some interval. "Time of day" metering allows electric rates to be changed during a day, to record usage during peak high-cost periods and off-peak, lower-cost, periods. Also, in some areas meters have relays for response load shedding during peak load periods [1]. Watt hour meter or energy meter is an instrument which measures amount of electrical energy used by the consumers [1]. Utilities install these instruments at every place like homes, industries, organizations to charge the electricity consumption by loads such as lights, fans and other appliances. Basic unit of power is watts. One thousand watts is one kilowatt. If we use one kilowatt in one hour, it is considered as one unit of energy consumed. These meters measure the instantaneous voltage and currents, calculate its product and gives instantaneous power. This power is integrated over a period which gives the energy utilized over that time period. These may be single or three phase meters depending on the supply utilized by domestic or commercial installations. For small service measurements like domestic customers, these can be directly connected between line and load. But for larger loads, step down current transformers must be placed to isolate energy meters from higher currents.

\section{Review of related works}

Hong and Ning [2] in their paper, proposed the use of Automatic Meter Reading (AMR) using wireless networks. Some commercial AMR products use the internet for data transmission.

Ling et al [3] utilized digital signal processors (DSP)-based meter to measure the electricity consumption of multiple users in a residential area. A Personal Computer (PC) at the control center was used to send commands to a remote

\footnotetext{
${ }^{*}$ Corresponding author: Barida Baah

Department of Computer Science, Ebonyi State University, Abakaliki- Nigeria.

Copyright (@) 2022 Author(s) retain the copyright of this article. This article is published under the terms of the Creative Commons Attribution Liscense 4.0.
} 
meter, which in turn transmitted data back, using the power Line Communication (PLC) technique. The major problem with this system is that it cannot detect tampering by consumers.

\subsection{Basic types of energy meters}

According to Dyer [4], Energy meter or watt hour meter is classified in accordance with several factors such as:

- Type of display like analog or digital electric meter.

- $\quad$ Type of metering point like grid, secondary transmission, primary and local distribution.

- $\quad$ End applications like domestic, commercial and industrial.

- $\quad$ Technical like three phases, single phase, High Type, Low Type and accuracy class meters.

\subsubsection{In accordance with all the factors, energy meters were classified into three basic types:}

- $\quad$ Electromechanical/induction Energy meter

- $\quad$ Electronic Energy meters

- $\quad$ Smart Energy Meters/prepaid energy Meters

\subsubsection{Electromechanical/induction type Energy meter}

It is the popularly known and most common type of old watt hour meter. It consists of rotating aluminum disc mounted on a spindle between two electro magnets. Speed of rotation of disc is proportional to the power and this power is integrated by the use of counter mechanism and gear trains. It comprises of three silicon steel laminated electromagnets as illustrated in figure 1.

- $\quad$ Series magnet carries a coil which is of few turns of thick wire connected in series with line.

- $\quad$ Shunt magnet carries coil with many turns of thin wire connected across the supply.

- $\quad$ Breaking magnet is a permanent magnet which applies the force opposite to normal disc rotation to move that disc at balanced position and to stop the disc while power is off.

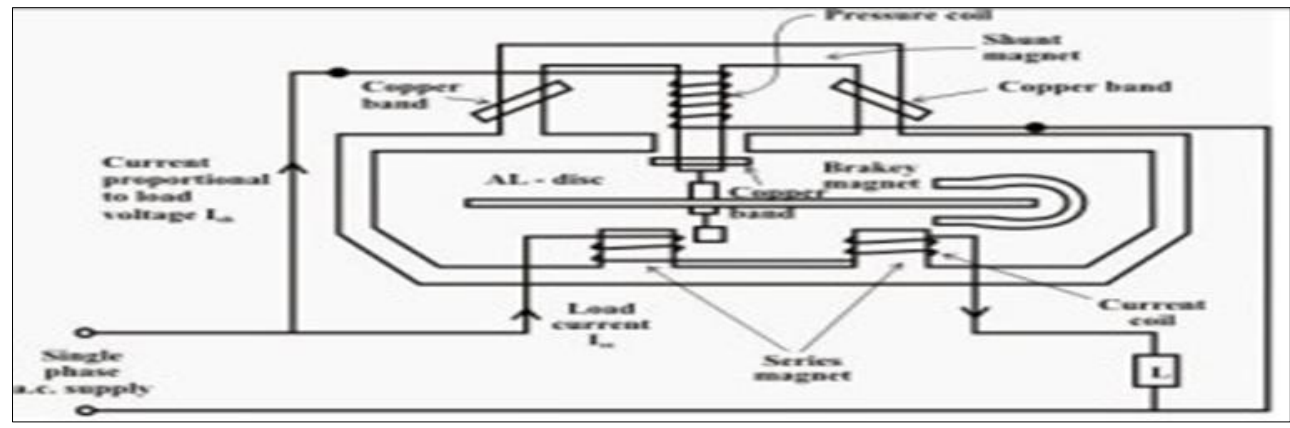

Figure 1 Internal Circuit of Electromechanical/Induction Type Energy Meter; (Source: Dyer [4])

The electromechanical induction meter operates by counting the revolutions of a non-magnetic, but electrically conductive, metal disc which is made to rotate at a speed proportional to the power passing through the meter. The number of revolutions is thus proportional to the energy usage [5]. On a single-phase AC supply, the electromechanical induction meter operates through electromagnetic induction by counting the revolutions of a non-magnetic, but electrically conductive, metal disc which is made to rotate at a speed proportional to the power passing through the meter. The number of revolutions is thus proportional to the energy usage. The voltage coil consumes a small and relatively constant amount of power, typically around two watts which is not registered on the meter. The current coil similarly consumes a small amount of power in proportion to the square of the current flowing through it, typically up to a couple of watts at full load, which is registered on the meter. The disc is acted upon by two sets of induction coils, which form, in effect, a two phase linear induction motor [5]. One coil is connected in such a way that it produces a magnetic flux in proportion to the voltage and the other produces a magnetic flux in proportion to the current. The field of the voltage coil is delayed by 90 degrees, due to the coil's inductive nature, and calibrated using a lag coil. This produces eddy currents in the disc and the effect is such that a force is exerted on the disc in proportion to the product of the instantaneous current, voltage and phase angle (power factor) between them. A permanent magnet acts as an eddy current brake, exerting an opposing force proportional to the speed of rotation of the disc. The equilibrium between these two opposing forces results in the disc rotating at a speed proportional to the power or rate of energy 
usage. The disc drives a register mechanism which counts revolutions, much like the odometer in a car, in order to render a measurement of the total energy used. Different phase configurations use additional voltage and current coils.

\subsubsection{Electronic Energy Meters}

These are of accurate, high procession and reliable types of measuring instruments as compared to conventional mechanical meters. It consumes less power and starts measuring instantaneously when connected to load. Electronic meters display the energy used on Liquid Crystal Display or Light Emitting diode display, and some can also transmit readings to remote places. In addition to measuring energy used, electronic meters can also record other parameters of the load and supply such as instantaneous and maximum rate of usage demands, voltages, power factor and reactive power used. They can also support time-of-day billing, for example, recording the amount of energy used during onpeak and off-peak hours. These meters might be analog or digital. In analog meters, power is converted to proportional frequency or pulse rate and it is integrated by counters placed inside it. In analog type meters, voltage and current values of each phase are obtained by voltage divider and current transformers respectively which are directly connected to the load as shown in figure 2.

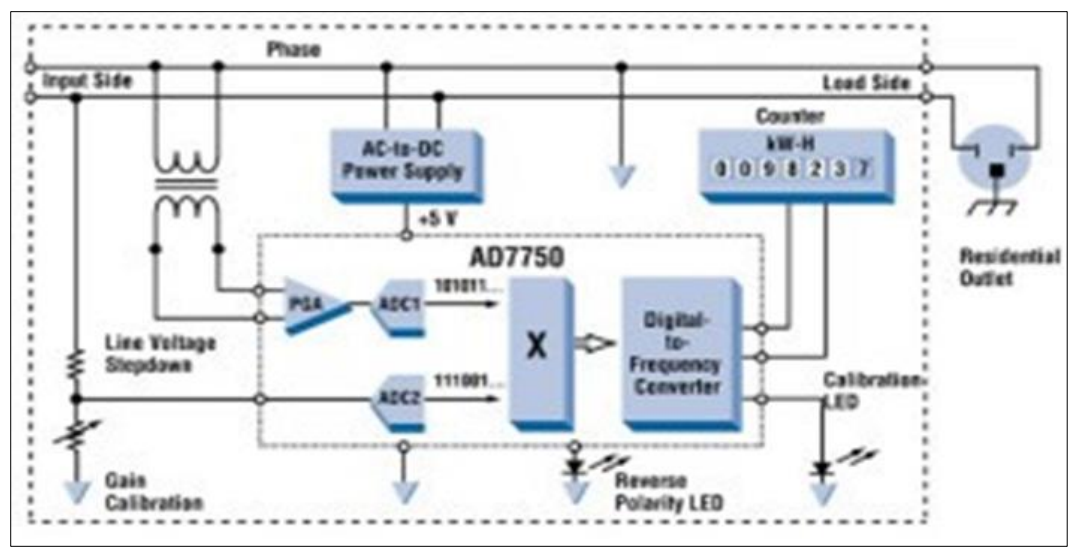

Figure 2 Internal Circuit of Analog Electronic Energy Meters

For digital electric meter power is directly measured by high end processor. The power is integrated by logic circuits to get the energy and also for testing and calibration purpose [6]. It is then converted to frequency or pulse rate. Digital Energy Meters are the $2^{\text {nd }}$ generation of Energy Meters. These meters digitally measure the energy and other factors like voltage, current, instantaneous Power and show them on a Liquid Crystal Display. They can store energy consumption data up to 2 years' in EEPROM (electrically erasable programmable read only memory). Figure 3 indicate the Internal Circuit of Digital Electronic Energy Meters.

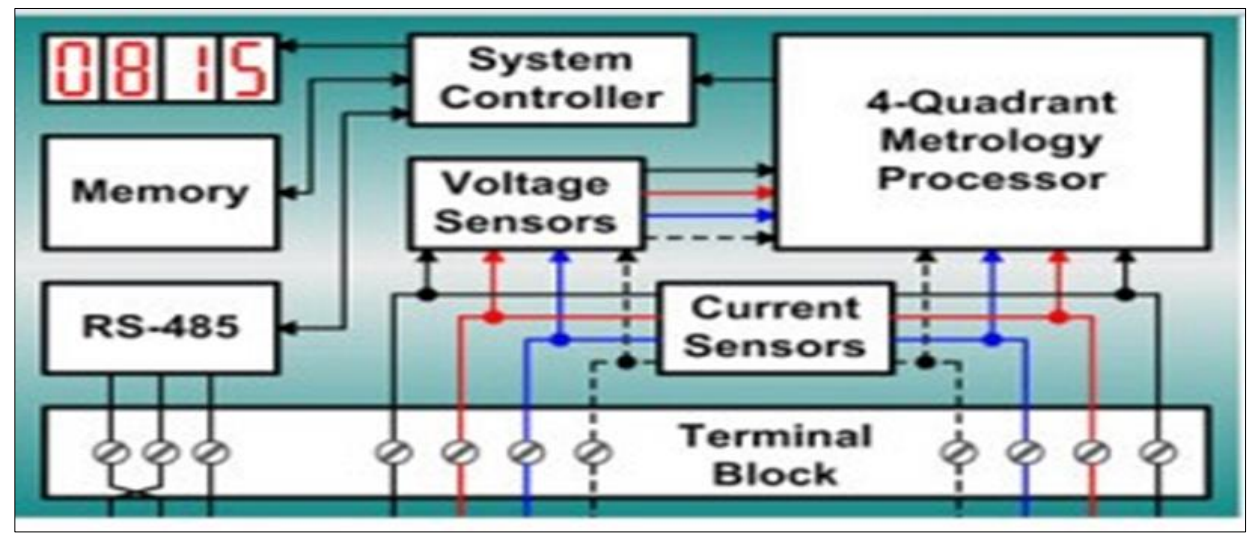

Figure 3 Internal Circuit of Digital Electronic Energy Meters

Digital Energy Meters came in single phase and three phases. Single phase type digital energy meters normally just display and store Energy units. Three phase energy meters give tariff based energy units. As the rate of the unit is more at Peak Load times than at off peak load times, energy meters must store energy units in two slots: peak slot (T1) and off peak slot (T2) to differentiate the timing of electricity usage. 
The metering engine is given the voltage and current inputs and has a voltage reference, samplers and quantizes followed by an ADC (analog digital converter) section to yield the digitized equivalents of all the inputs. These inputs are then processed using a digital signal processor to calculate the various metering parameters. The largest source of long-term errors in the meter is drift in the preamp, followed by the precision of the voltage reference. Both of these vary with temperature as well, and vary wildly because most meters are outdoors. The processing and communication section has the responsibility of calculating the various derived quantities from the digital values generated by the metering engine. This also has the responsibility of communication using various protocols and interface with other add on modules connected as slaves to it.

RTC (real-time clock) and other add-on modules are attached as slaves to the processing and communication section for various input/output functions. On a modern meter most if not all of this will be implemented inside the microprocessor, such as the real-time clock (RTC), LCD controller, temperature sensor, memory and analogue to digital converters.

\subsubsection{Smart Energy/Prepaid Energy Meters}

It is an advanced metering technology involving placing intelligent meters to read, process and feedback the data to customers. It measures energy consumption, remotely switches the supply to customers and remotely controls the maximum electricity consumption [6]. Smart metering system uses the advanced metering infrastructure (AMI) system technology for better performance as in figure 4 .

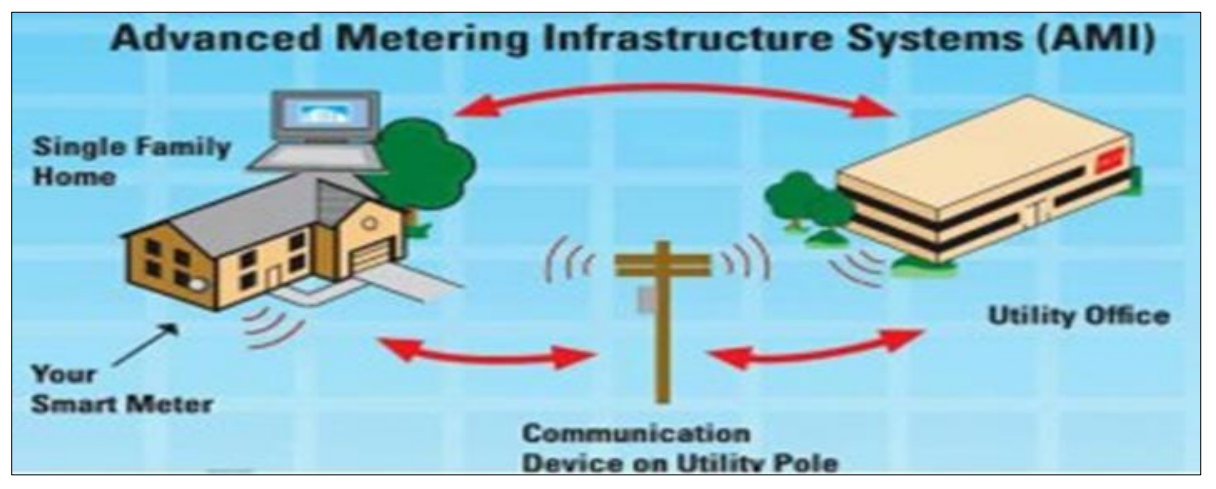

Figure 4 Advanced Metering Infrastructure (AMI) System Technology; (Source Koay [6])

Figure 4 are capable of communicating in both directions. They can transmit the data to the utilities like energy consumption, parameter values, alarms, etc and also can receive information from utilities such as automatic meter reading system, reconnect/disconnect instructions, upgrading of meter software's and other important messages. These meters reduce the need to visit while taking or reading monthly bill. Modems are used in these smart meters to facilitate communication systems such as telephone, wireless, fiber cable, power line communications. Another advantage of smart metering is complete avoidance of tampering of energy meter where there is scope of using power in an illegal way.

They can not only measure energy units but also send those units to the utility company through some communication medium like GSM/GPRS, Radio Frequency, PLC (Power Line Communication). Through these mediums company can control the load of consumer as well. While doing these basic responsibilities, these meters can also be used for load management and load forecasting purposes.

Kwan [7] identifies two types of smart meter which are as follows:

- $\quad$ AMR Smart Energy meters

- $\quad$ AMI Enabled Smart Energy meter

- $\quad$ Smart Card Based Prepaid Energy Meters

- $\quad$ Token based prepaid energy meter

\section{AMR Smart Energy meters}

AMR stands for Automatic meter reading. AMR Energy Meters are those Smart Energy Meters which measures the energy units and send it to the server. No other advantages like load management or load forecasting can be taken from 
these meters, only one sided communication taken place in this kind of energy meters i.e. from energy meter to the server.

\section{AMI Enabled Smart Energy meter}

AMI stands for Advanced Metering Infrastructure. They are the latest energy meters which were given complete package to ensure reliable and efficient energy management. They enable the utility company to communicate in both directions i.e. from server to the energy meter and vice versa. The advantage of two-way communication is that company can control the consumer load from their office and can also restrict the consumers to some specific load level. The addition of smart metering system into power grid station consists of implementation of the diversity of new technological techniques, software applications and hardware components [8].

The smart metering system features depend upon the requirements of electric power supply companies. These electric power companies will have capable power infrastructure, which will be integrated with information technology and communication features to deliver the electric power to consumers. Their bidirectional communication mechanism and electricity flow enables both electric power supply company and consumers to control, predict, manage and monitor the electricity consumption [9]. Furthermore, the usage of information technology and innovative communication infrastructure continue to modernize the industries but, in some countries, the electric power supply companies have retained the old infrastructures since decades. The increasing electric power consumption and a greater demand of electric power causes more technical problems for the electric power supply companies, such as, electric power shortfall, voltage sags, overload transformers, electricity theft and regular load shedding.

\section{Smart Card Based Prepaid Energy Meters}

In this type of prepaid energy meter, there are two main components [3]; one is smart card and another one is smart card reader. Smart card is like credit cards made of plastic and it consists of different components like Central Processing Unit, Read Only Memory, EEPROM. There is a whole smart card operating system through which data is controlled of a smart card. In this kind of scheme, the consumer must recharge his card as much number of units he wants. Later, that card is inserted into card reader which is embedded with energy meter like a whole package. Afterwards, card reader does its work and stores the units which are available in smart card; energy meter reduces the units as much electricity is being consumed. When unit reaches to zero, it disconnects the electricity until recharge.

\section{Token based prepaid energy meter}

Token based prepaid meter operates like GSM phones where generated tokens are used to recharge the devices. The token can be twenty digits, more or fewer digits, these token are generated by the electric energy providing companies at the point of purchase. The customers are supposed to key in the tokens into the devices to refill the energy from the source. It consists of 2 EEPROMs interfaced to a microcontroller. One EEPROM contains the recharged balance amount. The microcontroller reads this balance and stores it in the other EEPROM along with the tariff. The energy meter supplies pulses to the microcontroller for every unit of energy consumed. The microcontroller increases the spent energy unit by one and decreases the balance amount in the EEPROM by the fixed tariff. As soon as the balance amount in the EEPROM comes down to zero, the microcontroller sends a signal to the relay driver which in turn switches off the relay, such that the main supply to the load is switched off. An LCD is also interfaced to the microcontroller which displays the amount of energy consumed

\subsection{Energy Meters Metering}

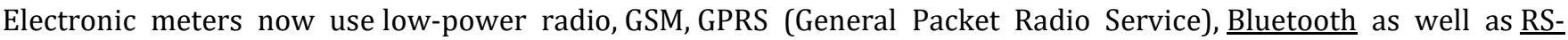
$\underline{485}$ wired link. The meters can now store the entire usage profiles with time stamps and relay them at a click of a button. The demand readings stored with the profiles accurately indicate the load requirements of the customer. This load profile data is processed at the utilities for billing and planning purposes. AMR (Automatic Meter Reading) and $R M R$ (Remote Meter Reading) describe various systems that allow meters to be checked without the need to send a meter reader out. An electronic meter can transmit its readings by telephone line or radio to a central billing office. Automatic meter reading can be done with GSM (Global System for Mobile Communications) modems, one is attached to each meter and the other is placed at the central utility Office. According to Ning, [2], there are four types of metering in energy meters, they are:

- $\quad$ Time of day metering

- $\quad$ Remote metering

- $\quad$ Standards metering

- $\quad$ Power export metering 


\subsubsection{Time of day metering}

Time of Day metering (TOD), also known as Time of Usage (TOU) or Seasonal Time of Day (SToD) metering involves dividing the day, month and year into tariff slots and with higher rates at peak load periods and low tariff rates at offpeak load periods. While this can be used to automatically control usage on the part of the customer (resulting in automatic load control), it is often simply the customer's responsibility to control his own usage, or pay accordingly (voluntary load control). This also allows the utilities to plan their transmission infrastructure appropriately. TOD metering normally splits rates into an arrangement of multiple segments including on-peak, off-peak, mid-peak or shoulder, and critical peak. A typical arrangement is a peak occurring during the day (non-holiday days only), such as from $1 \mathrm{pm}$ to $9 \mathrm{pm}$ Monday through Friday and from 6:30 am to 12 noon and $5 \mathrm{pm}$ to $9 \mathrm{pm}$. More complex arrangements include the use of critical peaks which occur during high demand periods. The times of peak demand/cost will vary in different markets around the world. Large commercial users can purchase power by the hour using either forecast pricing or real time pricing.

\subsubsection{Remote metering}

The idea of remote metering was born in the 1960s. Initially, remote pulse transmission was used, but this has gradually been replaced by using various protocols and communication media. Today meters with complex functionality are based on the latest electronic technology, using digital signal processing, with most functions being implemented in firmware [10].

\subsubsection{Standards metering}

The need for close co-operation between manufacturers and utilities was achieved relatively early. The first metering standard is the ANSI C12 Code for electricity metering was developed as early as 1910 [2]. Its Preface says: "While the Code is naturally based upon scientific and technical principles, the commercial side of the metering has been constantly kept in mind as of very great importance". The first known IEC metering standard, Publication 43, dates from 1931. The high standard of accuracy is an outstanding characteristic that was established and maintained by the metering profession. Leaflets from as early as 1914 feature meter with an accuracy of $1.5 \%$ over the measuring range of $10 \%$ or less to $100 \%$ of maximum current. IEC 43:1931 specifies accuracy class 2.0 . This accuracy is still seen as adequate for most residential applications today, even for static meters.

\subsubsection{Power export metering}

Many electricity customers are installing their own electricity generating equipment, whether for reasons of economy, redundancy or environmental reasons [2].. When a customer is generating more electricity than required for his own use, the surplus may be exported back to the power grid. Customers that generate back into the "grid" usually must have special equipment and safety devices to protect the grid components (as well as the customer's own) in case of faults (electrical short circuits) or maintenance of the grid (say voltage on a downed line coming from an exporting customer's facility). This exported energy may be accounted for in the simplest case by the meter running backwards during periods of net export, thus reducing the customer's recorded energy usage by the amount exported. This in effect results in the customer being paid for his/her exports at the full retail price of electricity. Unless equipped with a ratchet or equivalent, a standard meter will accurately record power flow in each direction by simply running backwards when power is exported. Where allowed by law, utilities maintain a profitable margin between the price of energy delivered to the consumer and the rate credited for consumer-generated energy that flows back to the grid. Lately, upload sources typically originate from renewable sources (e.g., wind turbines, photovoltaic cells), or gas or steam turbines, which are often found in cogeneration systems. Another potential upload source that has been proposed is plug-in hybrid car batteries (vehicle-to-grid power systems). This requires a "smart grid," which includes meters that measure electricity via communication networks that require remote control and give customers timing and pricing options. Vehicle-togrid systems could be installed at workplace parking lots and garages and at park and rides and could help drivers charge their batteries at home at night when off-peak power prices are cheaper, and receive bill crediting for selling excess electricity back to the grid during high-demand hours.

\section{Analysis of merits and demerits of meters}

In analysis the merits and demerits of meters types we will compare between the different types of energy meters in terms of its merits and demerits as shown in table 1. 
Table 1 Merits and Demerits of various types of energy meters

\begin{tabular}{|c|l|l|l|}
\hline SN & \multicolumn{1}{|c|}{ Meters Types } & \multicolumn{1}{|c|}{ Merits } & \multicolumn{1}{c|}{ Demerits } \\
\hline 1 & $\begin{array}{l}\text { Electromechanical/Induction } \\
\text { meter }\end{array}$ & $\begin{array}{l}\text { It is robust with respect to new } \\
\text { energy meter }\end{array}$ & $\begin{array}{l}\text { It does not give room for } \\
\text { future upgrade }\end{array}$ \\
\hline & It reading is pretty hard to alter & $\begin{array}{l}\text { It usually give accuracy } \\
\text { limits of class } 2\end{array}$ \\
\hline 2 & Smart Energy Meter & It does require the use of battery & $\begin{array}{l}\text { It is highly exposed } \\
\text { electricity stealers }\end{array}$ \\
\hline & & $\begin{array}{l}\text { Easy to monitor your energy usage } \\
\text { and spending using home display }\end{array}$ & $\begin{array}{l}\text { Home display maybe } \\
\text { inaccurate }\end{array}$ \\
\hline
\end{tabular}

\section{Test Result}

Table 2 show the general performance level of various types of energy meters like manual energy meter, prepaid energy meters, microcontroller based prepaid meter, GSM based prepaid metere and GSM based prepaid meter with ardiuno approach.

Table 2 Evaluation of Attendance Systems

\begin{tabular}{|l|c|c|c|c|}
\hline Method & \multicolumn{4}{|c|}{ Total Number of recharge and service in seconds } \\
\hline & $\mathbf{1}$ & $\mathbf{1 0}$ & $\mathbf{5 0}$ & $\mathbf{1 0 0}$ \\
\hline Manual energy meter & 604800 & 6048000 & 302400 & 60480000 \\
\hline prepaid energy meter & 172800 & 1728000 & 8640000 & 17280000 \\
\hline microcontroller based prepaid meter & 2800 & 28000 & 140000 & 280000 \\
\hline GSM based prepaid meter & 30 & 300 & 1500 & 3000 \\
\hline GSM based prepaid meter with arduino & 3 & 30 & 150 & 300 \\
\hline
\end{tabular}

\section{Conclusion}

We have been able to take a look at the various types of meter and their metering processes, in view of this we conclude that the choice of meter will depend on the capabilities of providing efficient power and good management system for both the power consumers and the electricity generating company. In comparism of this meters and metering; GSM based prepaid meter which belong to the class of smart meters that utilizes the arduino technology have proven to be the best compare to other meters in terms of service delivery and good information management system.

\section{Compliance with ethical standards}

\section{Disclosure of conflict of interest}

There is no conflict of interest among we the authors of this research work.

\section{References}

[1] Verne K, Ryan K. Google Plans Meter to Detail Home Energy Use. Retrieved December 17, 2019, from THE TECH CHRONICLES. 2009. 
[2] Hong, L, Ning L. Design and Implementation of Remote Intelligent Management System for City Energy Resources Base on Wireless Network Study of Computer Application. International Journal of Engineering, Science and Technology. 2004; 160-166.

[3] Ling Z, Sihong C, Biao G. The Design of Prepayment Polyphase Smart Electriicity Meter System. International Conference on Intelligent Computing and Integrated Systems (ICISS). 2010; 430-432.

[4] Dyer S. Survey of Instrumentation and Measurement. New York, USA: John Willey and Sons. 2001.

[5] Jehl F. Menlo Park Reminiscences. Kessinger Publishing. 2010.

[6] Koay BS, Cheah S, Sng YH, Chong P, Shun P, Tong Y. Design and Implementation of a Blue Tooth Energy Meter. IOSR Journal of Electrical and Electronics Engineering (IOSR-JEEE). 2013; 1474-1477.

[7] Kwan B, Moghavvemi M. PIC based smart card prepayment system. Student Conference on Research and Development. 2002; 7803-7565.

[8] Zahoor H, Shahzad M, Lachhman D, Muhammad HS, Jawad H. Issues and Challenges of Existing Electricity PrePaid Smart Metering Systems. A Review, Science, Technology and Development. 2017; 44-52.

[9] Cleverland F. Cyber Security Issues for Advanced Metering Infrastructure. Power and Energy Society General. 2008; 1-5.

[10] Harish M, Tech S. GSM Based Automatic Wireless Energy Meter Reading System International Journal of Engineering Research. 2012. 